\title{
How to Live with Rare Diseases in Serbia: The Knowledge and Attitudes of Patients Regarding Medical, Societal and Bioethical Aspects of this Issue
}

\author{
Branislava Medić ${ }^{1 *}$, Bojan Stopić ${ }^{2}$, Stojan Peric ${ }^{3}$, Vidosava Rakocevic Stojanovic ${ }^{3}$, \\ Dragana Lavrnic ${ }^{3}$, Katarina Savić Vujović ${ }^{1}$, Sonja Vučković ${ }^{1}$, Nevena Divac ${ }^{1}$, Radan \\ Stojanovic $^{1}$, Dragana Srebro ${ }^{1}$, Milica Prostran ${ }^{1}$ \\ ${ }^{1}$ Department of Pharmacology, Clinical Pharmacology and Toxicology, Faculty of Medicine, \\ University of Belgrade, Dr Subotića starijeg 1, Belgrade, Serbia \\ ${ }^{2}$ Faculty of Medicine, University of Belgrade, Belgrade, Serbia \\ ${ }^{3}$ Neurology Clinic, Department for Neuromuscular Disorders, Clinical Center of Serbia, \\ Faculty of Medicine, University of Belgrade, Dr Subotica 6, Belgrade, Serbia
}

\begin{abstract}
:
Introduction: We aimed to assess knowledge and attitudes of patients towards the issue of rare diseases in our community.

Material and methods: The cross-sectional study was conducted over five weeks on outpatients and inpatients at Department for Neuromuscular Disorders. A self-completed questionnaire was delivered to 60 patients. Total response rate was $95.83 \%$.

Results: Two thirds of the respondents (70.74\%) considered that know what kind of disease is defined as "rare". Despite that, only half of participants believed that suffer from rare disease. They considered that dealing with this issue in our country is extremely important (median value -9; interquartile range 8-10) and that situation of patients is difficult (median value - 3.5; interquartile range 1.25-7.75). Our respondents agreed that the most serious problems regarding rare diseases issue in Serbia are the following: lack of public information (21.83\%), lack of scientific knowledge (14.78\%), high prices of drugs (14.08\%), complicated procedures for their procurement (12.67\%) etc. Finally, pharmacotherapy of rare diseases in our country can be improved by: well-timed diagnostics, raising general awareness, registration of more appropriate drugs etc.
\end{abstract}

Conclusion: It is necessary to improve knowledge and attitudes of patients towards the issue of rare diseases and support them to form own association.

Keywords: rare diseases, attitudes, knowledge, pharmacotherapy, patients, Serbia.

\section{INTRODUCTION}

According to data from the EU, disease can be defined as rare when affects 1 person in 2000 or 5 in 10000 people in population (there are so rare diseases that occur 1 person in 100000,1 person in 1 000000 or even less) [1].

The most relevant facts concerning rare diseases (RDs) are as following: 1 . These diseases are often chronic, progressive, degenerative and life-threatening, 2. $80 \%$ of rare diseases have identified genetic origins, 3. The first symptoms appear at birth or in early childhood, $4.75 \%$ of rare diseases affect children (30\% of rare disease patients die before age of 5), 5. Rare diseases are disabling: the quality of life of patients is often compromised by the lack or loss of autonomy etc. Until today it is described more than 7000 rare diseases, and their number is constantly increasing. European Organisation for Rare Diseases (EURORDIS) estimates that nearly 30 million people in EU countries suffer from some rare diseases, while in Serbia, according to unofficial data, this number is around 500000 patients [2]. Patients suffering from RDs are faced with numerous problems: lack of public and scientific knowledge of the disease, lack of quality information on the disease, delay in diagnosis (or lack of access to correct diagnosis), heavy social consequences (stigmatization, isolation, discrimination, reducing professional opportunities etc.), lack of appropriate quality healthcare, high prices of these drugs and complicated procedures for their procurement etc. [3]. 
Although national legislation ensures the availability of drugs for those diseases, there is not a National Register and National Plan for Rare Diseases in Serbia. Pharmacotherapy of rare diseases in our country is also challenged with many difficulties: the lack of a sufficient number of registered drugs, licensed drugs are not always available, provision of unlicensed medicines is very difficult, not just due to legislative obstacles and the fact that these drugs are often found in private pharmacies at very high prices and without adequate supervision [4].

After all mentioned, it should be noted that patients suffering from RDs certainly belong to vulnerable groups [5]. Development and availability of drugs for RDs could challenge basic bioethical principles. Utilitarian concept could not be fully applied in this matter since it favours development of drugs for common disorders insead of the rare one. One could argue that diseases are rare but there are a lot of patients suffering from them [6].

Our research group deal with different aspects regarding rare diseases in our community: pharmacotherapy, bioetical issues, social significance, importance of education among medical students and professionals etc.

The aim of this study was to evaluate knowledge and attitudes of patients regarding medical, societal and bioethical aspects of rare diseases in Serbia.

\section{MATerials AND MethodS}

\subsection{Participants}

The cross-sectional study was conducted over five weeks on outpatients and inpatients (Neurology Clinic, Department for Neuromuscular Disorders, Clinical Center of Serbia). The participants were recruited during regular controls. All patients suffered from rare neurological diseases.

\subsection{Questionnaire}

All participants completed an anonymous questionnaire entitled "Knowledge and attitudes of patients regarding rare diseases in Serbia". The questionnaire was developed at the Department of Pharmacology, Clinical Pharmacology and Toxicology, Faculty of Medicine, University of Belgrade and reviewed by two experts on rare neurological diseases. The questionnaire was approved by the Ethics Committee of the Faculty of Medicine in Belgrade (Number 32/XI-14).

Both closed and open questions were used when appropriate. The questionnaire consisted of general data (such as gender, age, diagnosis etc.), questions concerning awareness of rare diseases and their treatment, attitudes regarding problems of these patients, as well as the possibilities of overcoming them. Patients' attitudes were assessed by the 10-point Likert scale.

\subsection{Statistics}

The results were presented as descriptive statistics (nominal scale) and median value and interquartile range. A statistical analysis was performed using $\chi^{2}$ test and Mann-Whitney $U$ test, with a statistical significance level of 0.05 .

\section{RESUltS}

\subsection{General Characteristics of the Participants}

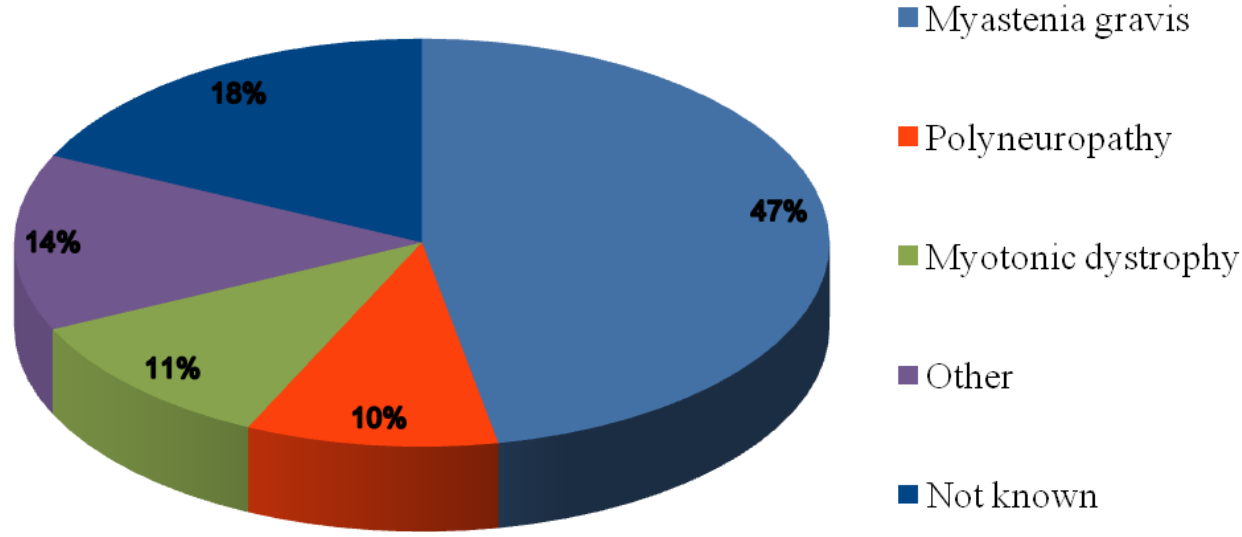

Graph1. Percentage of diseases in our respondents 
How to Live with Rare Diseases in Serbia: The Knowledge and Attitudes of Patients Regarding Medical, Societal and Bioethical Aspects of this Issue

The questionnaire was completed by a total of 60 patients, of whom $39(65 \%)$ patients were male and $21(35 \%)$ were female. The mean age was $47.78 \pm 14.20$.

Fifty of participants $(83.33 \%)$ were aware of the diagnosis of their disease. They reported the following diagnosis: myasthenia gravis - 27 patients (54\%), myotonic dystrophy - 6 patients (12\%), polyneuropathy - 6 patients (12\%), multiple sclerosis - 2 patients $(3.33 \%)$, syringomyelia - 1 patients $(2 \%)$, amyotrophic lateral sclerosis - 1 patients $(2 \%)$, myelopathy -1 patients $(2 \%)$, and parkinsonism - 1 patients (2\%) (Graph 1).

\subsection{Patients' Knowledge and Attitudes Concerning Rare Diseases in General and Treatment Possibilities}

Two thirds of respondents (70.74\%), considered that know what kind of disease is defined as "rare". (Graph 2A). Despite that, only half of participants believed that suffer from rare disease (Graph 2B). In addition, the prevalence of rare diseases according to EU standards was correctly estimated by a slightly more than third of participants.

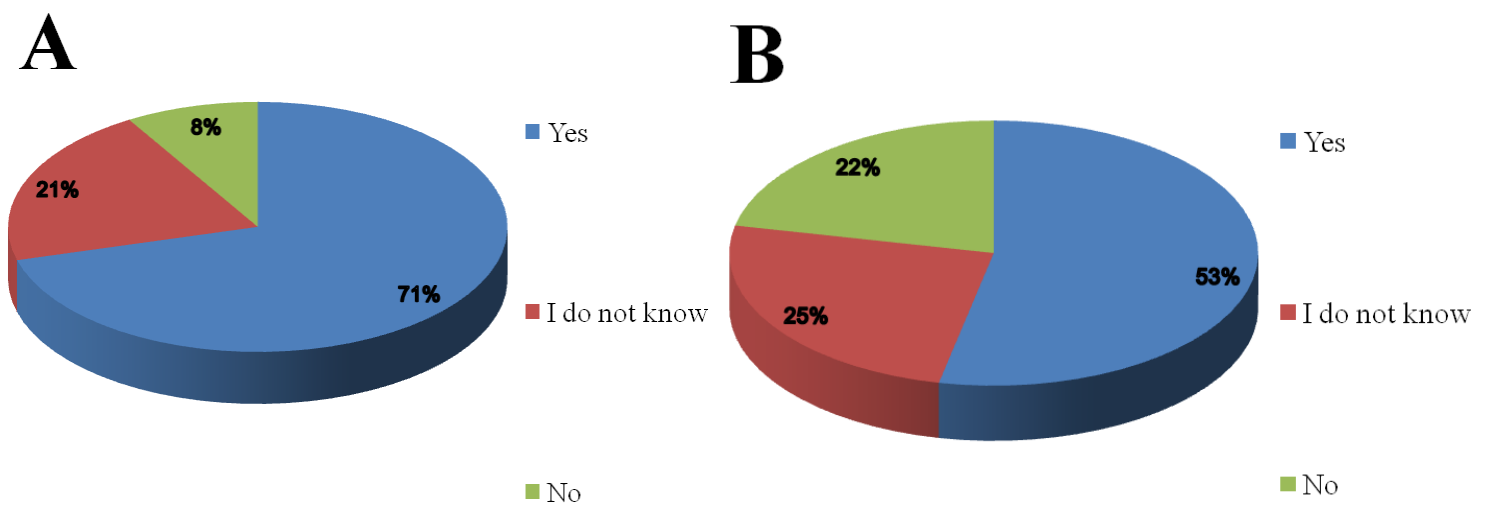

Graph2.A: Do you know what is a rare disease? B: Do you suffer from any of the rare diseases?

Using the 10-point Likert scale (1 - not important at all, 10 - the most important) participants rated the importance of rare diseases issue in our society as one of the most essential. (median value - 9; interquartile range 8-10) (Figure 1, Panel A).

The overall quality of healthcare of patients suffered from RDs in general in our community was rated low (median value - 3.5; interquartile range 1.25-7.75) (Figure 1, Panel B).

The most important problems faced by patients suffering from rare diseases in Serbia are: lack of public information (21.83\%), lack of scientific knowledge (14.78\%), high prices of drugs (14.08\%), complicated procedures for their procurement (12.67\%), lack of access to correct diagnosis $(12.67 \%)$, lack of registered drugs for rare diseases $(11.9 \%)$, lack of appropriate quality healthcare $(6.3 \%)$, legislation obstacles (4.9\%), unavailability of these drugs in private pharmacies (0.7\%) (Graph 3).

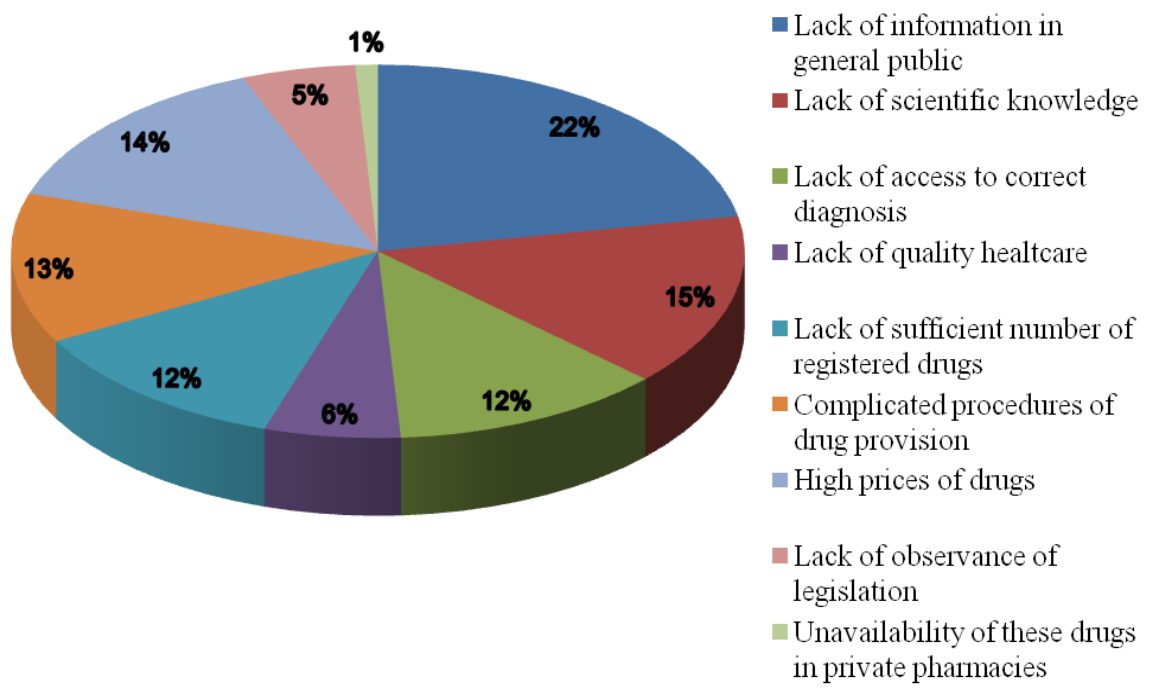

Graph3. The most important problems of patients suffering from rare diseases? 
Availability of drugs for rare diseases in our country was rated as very poor (median value - 2; interquartile range 1-6) (Figure 1, Panel C). According to our participants, availability of drugs for rare diseases can be improved by greater involvement of: the state $(55 \%)$, medical doctors $(30 \%)$, pharmaceutical companies and pharmacies $(10 \%)$, associations of patients suffering from rare diseases $(3.33 \%)$ and other institutions $(1.66 \%)$.

\subsection{Patients' Attitudes Regarding Rare Diseases as a Societal and Bioethical Issue}

We considered it significant to ask patients whether they are members of an association of patients suffering from RDs. Only 10 of them (16.6\%) confirmed a membership in some of patients' organizations (Graph 4A). Beside that, we checked our participants' attitudes regarding participation in clinical trials that deal with drugs for rare diseases. The voluntary consent to participate in this kind of research expressed just slightly more than a quarter of our respondents (26.6\%) (Graph 4B).
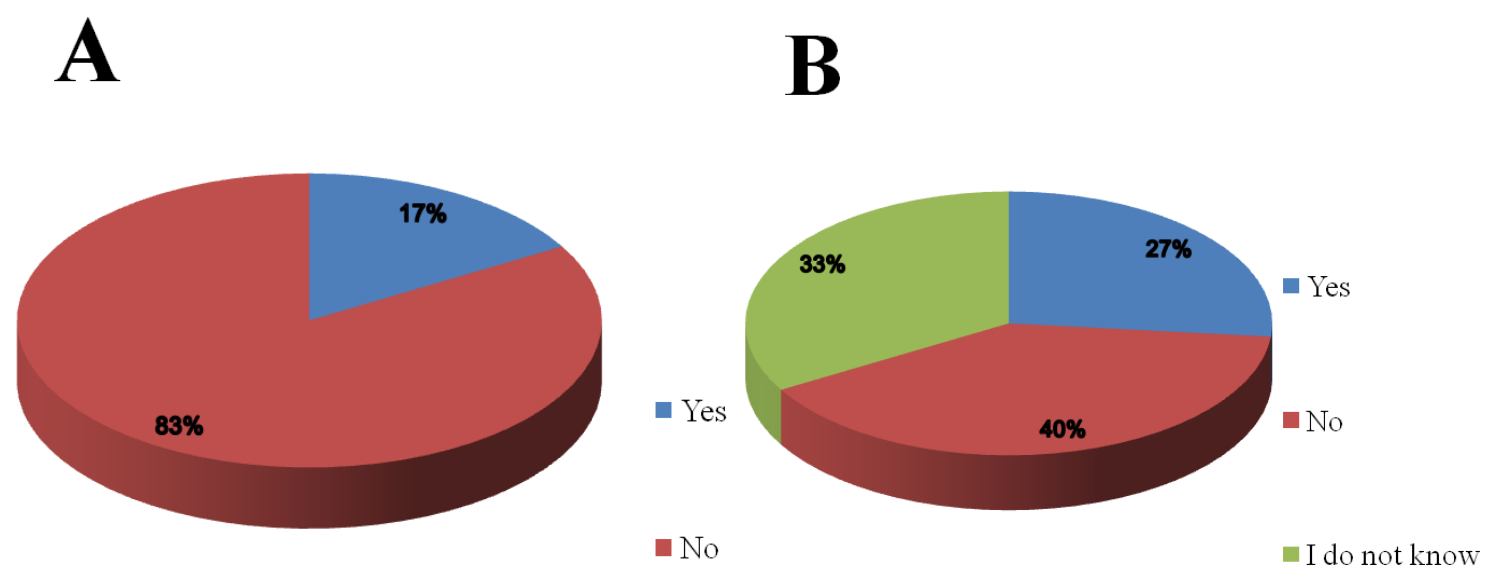

Graph4. A: Are you a member of an association of patients suffering from rare diseases? B: Would you be willing to participate in clinical trials that examine orphan drugs?

Our respondents are also demanded to rate ethical justification of investment significant financial resources in treatment of patients suffering from RDs (10-point Likert scale, median value - 10; interquartile score 8.25-10) (Figure 1, Panel D).

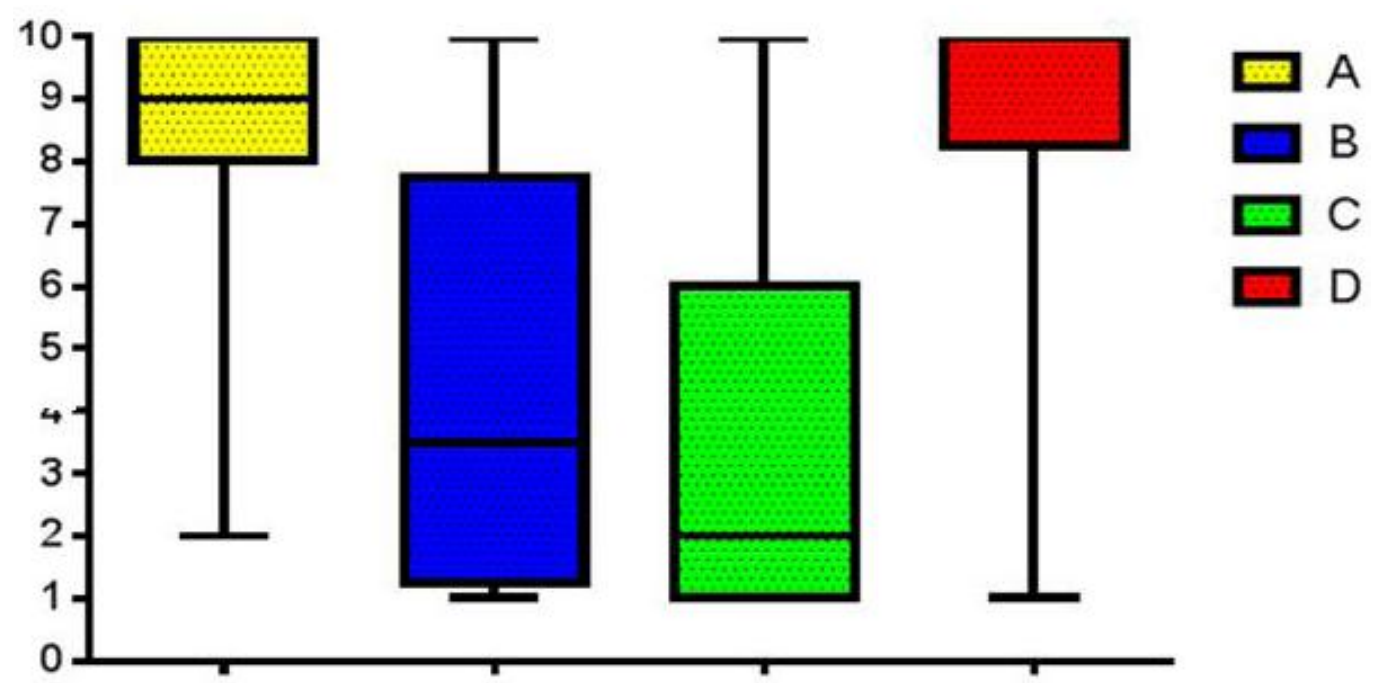

Figure1. The average values of the selected scores (median value, interquartile range 25-75\%) of examined patients concerning their attitudes and awareness towards the issue of rare diseases in our community. Panel A: How do you rate the importance of issue of rare diseases in Serbia? (scale 1-10), Panel B: How do you rate overall quality of healthcare of patients with rare diseases in our community? (scale 1-10), Panel C: How do you rate the availability of drugs for rare diseases in Serbia (scale 1-10), Panel D: How do you rate ethical justification of investment significant financial resources in treatment of patients suffering from RDs (scale 110). The results are shown in a graph box ("Box plot") with a median value and interquartile range (25--75\%).

Finally, in order to improve the pharmacotherapy of rare diseases in Serbia, the participants suggested the following: well-time diagnostics (25.78\%), raise the general awareness $(22.64 \%)$, simplified drug approval processes $(16.9 \%)$, registration of more appropriate drugs $(11.3 \%)$, creating rare diseases 
How to Live with Rare Diseases in Serbia: The Knowledge and Attitudes of Patients Regarding Medical, Societal and Bioethical Aspects of this Issue

patient registries (7.6\%), establishment of the National Strategy for RDs (6.2\%), full implementation of legislation on this matter (4.7\%) adequate control of drugs available in private pharmacies in Serbia (4.25\%) (Graph 5).

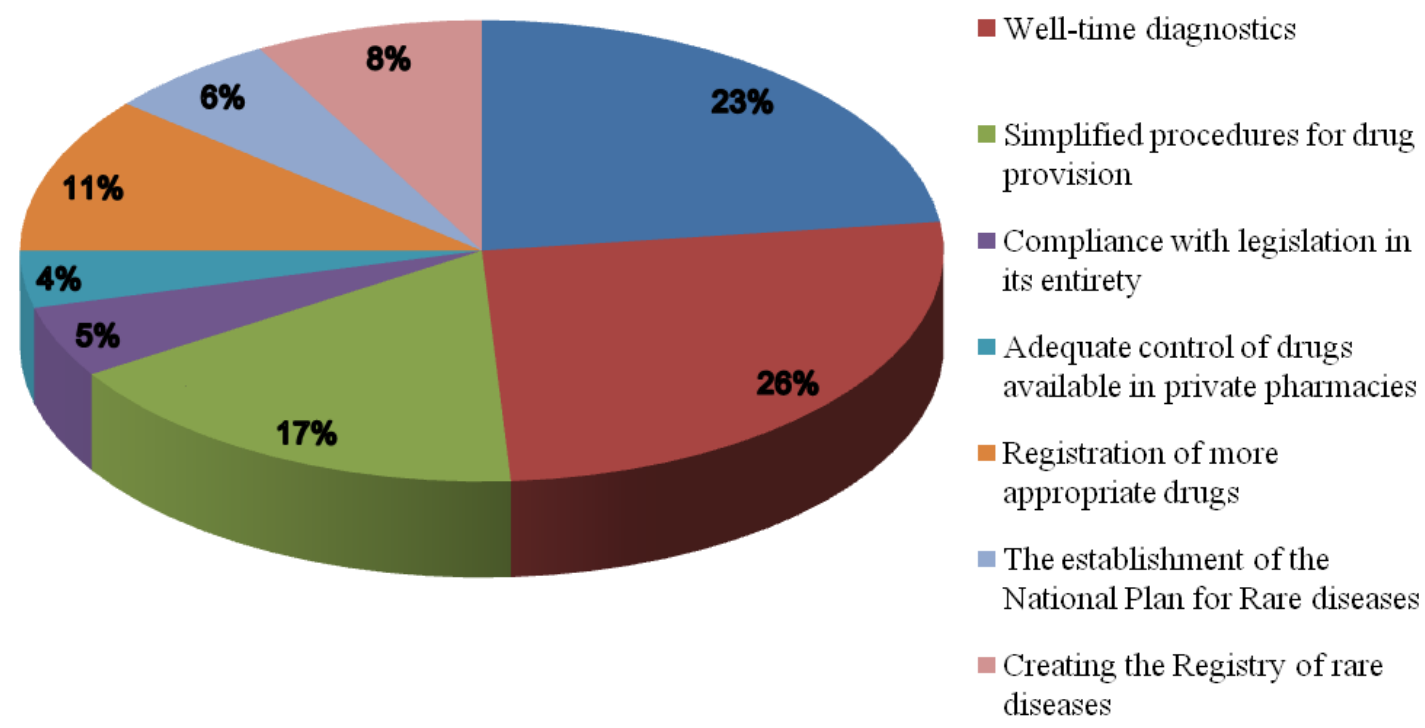

Graph5. How to improve pharmacotherapy of rare diseases in Serbia?

\section{DisCUSSION}

In general, our survey showed that respondents were very interested to express their attitudes regarding the rare diseases issue in our country. This is confirmed by the high percentage of provided answers (total response rate was 95.83\%). Although the majority of respondents stated that know what term "rare disease" represents $(69.5 \%)$, only half of them confirmed that suffer from some of these diseases (53.3\%). This finding suggests the lack of information about their own illness (all participants suffered from RDs, from the group of neurological disorders, according to EU standards Orphan Drug Regulation 141/2000) [1].

Using the 10-point Likert scale, respondents estimated the importance of rare diseases in our society as a problem of crucial importance. Here we noticed a significant difference in attitudes between patients and $3^{\text {rd }}$ and $6^{\text {th }}$ year medical students that we have examined previously (patients $9 v s .3^{\text {rd }}$ year 5.9 and $6^{\text {th }}$ year $5.8, \mathrm{P}<0.01$ ). In opposite, observed patients and future medical doctors showed similar opinion regarding the overall quality of healthcare of patients affected with rare diseases in general (10-point Likert scale, patients 3.5 vs. $3^{\text {rd }}$ year 2.2 and $6^{\text {th }}$ year $\left.2.4, \mathrm{P}<0.05\right)$ [7].

We should say that understanding of such complex issue such pharmacotherapy of rare disease is, requires knowledge of basic principles of biomedical ethics, which are intended to facilitate and promote the work of health professionals and to improve the quality of life of patients [8-10].

We have already discussed that patients suffering from rare diseases could be assumed as vulnerable subjects [11]. It is important to notice that promotion of basic European principles of bioethics (autonomy, dignity, integrity and vulnerability) is not always possible and suitable regarding these patients [12].

Our respondents agreed that the most important problems of patients suffered from RDs in Serbia were the following: lack of public and scientific knowledge concerning this issue, unsufficent number of registered drugs, high prices of drugs and complicated procedures for their procurement, inadequate healthcare of these patients, legislative obstacles etc. Similar observations were noted among medical students [7], as well as among healthcare professionals (physicians and clinical pharmacists) in a pilot study performed at the University Hospital "Bežanijska kosa" in Belgrade (unpublished data from our group).

The participants estimated that greater involvement of the state is needed in order to improve availability of drugs for RDs. However, the activities of the state are actually dependent on professionals' (policy makers, members of the regulatory bodies, medical doctors) knowledge and attitudes, as well as active participation of patients in national policy making. Our survey suggests that 
patients do not participate enough in these activities (only $16.6 \%$ of them confirmed a membership in some of patients' organizations and slightly more than a quarter of our respondents expressed will to participate in clinical trials that examine these drugs). Related to these findings, Baker scrutinized that reference to collective responsibility in the situation of existence of a problem, can lead to a complete denial of the existence of individual responsibility, which is not ethically right, and does not lead to substantive resolution of the issue [13].

The role of medical professionals in process of recognisation this issue as the important societal and bioethical concern is extremly sifnificant and undeniable. According to Trisnadi medical profession have two crucial assignments: "1) to apply a set of systematically arranged knowledge of the problematics of the specific problems; and 2) those problems have important relevance in accordance with the fundamental values considered by the community"[14].

Beside that, in medical practice it has often discussed whether is justified to invest a large amount of money in the pharmaceutical industry, especially regarding the "medicalization" of society, last three decades [15]. In contrast, in the treatment of patients suffering from rare diseases we have a real need for the drug, but the lack of interest in the pharmaceutical industry in their development is evident [16].

Our respondents considered it quite reasonably and ethically justified to invest large amounts of money to treat a small number of patients. On the other hand, the $3^{\text {rd }}$ and $6^{\text {th }}$ year medical students preferred, without differences, that they would rather invest on drugs for more common conditions affecting larger numbers of people in comparasion on drugs for rare diseases (10-point Likert scale, patients 10 vs. $3^{\text {rd }}$ year 7.9 and $6^{\text {th }}$ year $\left.7.9 ; \mathrm{P}<0.05\right)[7]$.

Finally, in order to improve the pharmacotherapy of rare diseases in Serbia, patients suggested the following: raising general and scientific knowledge, well-time, simplified procedures for drug provision, registration of more appropriate drugs etc.

We would like to stressed out that in this moment our country has already started numerous projects with particular aim to create national strategy focused on registries, centers of expertise, improvement of access to medicines etc. Concerning this, we believe that this is the critical moment for conducting public discussion on rare diseases which should involve not just medical professional and regulatory bodies, but the patients suffering from RDs as well.

\section{Conclusion}

We can conclude that our participants showed will to express their attitudes regarding this important medical, societal and bioethical concern in our community. Patients are aware of the most important problems regarding diagnostics and treatment possibilities of rare diseases.

However, we need to note that patients showed insufficient knowledge on their own illness, unwillingness to participate in clinical trials that investigate drugs for rare diseases and poorly take participation in patients' organizations.

Therefore, we consider it is necessary to improve patient awareness regarding the problems of pharmacotherapy of rare diseases and encourage them to organize their own associations in order to enhance their position in our country.

\section{ACKNOWLEDGEMENT}

This work was supported by the Ministry of Education, Science and Technological Development of Serbia (Grant No. 175023).

\section{REFERENCES}

[1] Rare Diseases Europe (EURORDIS): About rare diseases [Online] Available from URL http://www.eurordis.rs/ about-rare-diseases [access 2015 november]

[2] Serbian National Organization for Rare Diseases (NORBS): About rare diseases [Online] Available from URL http://www.norbs.rs/ norbs-o-retkim-bolestima.php [access 2015 november] (Serbian)

[3] Rulebook on the List of Drugs Covered by Health Insurance. Official Gazette of the Republic of Serbia No.1/2012 (Serbian) 
How to Live with Rare Diseases in Serbia: The Knowledge and Attitudes of Patients Regarding Medical, Societal and Bioethical Aspects of this Issue

[4] Ten years of orphan medicines legislation in Europe - European Medicines Agency reviews success and looks ahead. [http://www.ema.europa.eu /pdfs/general/direct/pr/29156010en.pdf] [access 2015 december]

[5] CIOMS, International Ethical Guidelines for Biomedical Research Involving Human Subjects. Available from: www.cioms.ch/publications/layout_guide2002.pdf [access 2016 january]

[6] Taylor CM, Karet Frankl FE. Developing a strategy for the management of rare diseases. BMJ 344, e2417, (2012).

[7] Medić B, Divac N, Stopić B, Savić Vujović K, Glišić A, Cerovac N, Stojanović R, Srebro D, Prostran M. The attitudes of medical students towards rare diseases: A cross-sectional study. Vojnosanit Pregl. Online First September (00), 94-94, (2015).

[8] Macklin R: Applying the four principles. J Med Ethics. 29(5), Pp 275-280, (2009).

[9] Todorović Z, Prostran M, Medić B, Vučinić M: Bioehics and pharmacology. In: Bioethics and Pharmacology: Ethics in Preclinical and Clinical Drug Development. Edited by Todorović Z, Prostran M, Turza K. Kerala, India: Transworld Research Network. Pp 7-13, (2012)

[10] Beauchamp TL, Childress JF: Principles of Biomedical Ethics, 6th ed. Oxford: Oxford University Press; 2008.

[11] Prostran M, Todorović Z, Stojanović R, Potpara T, Nešić Z, Lazić J, Medić B: Bioethics in clinical trials: Vulnerable subjects. In: Bioethics and Pharmacology: Ethics in Preclinical and Clinical Drug Development. Edited by Todorović Z, Prostran M, Turza K. Kerala, India: Transworld Research Network. Pp 87-100, (2012).

[12] Kemp P, Rendtorff JD: The Barcelona Declaration: Towards an Integrated Approach to Basic Ethical Principles. Synthesis Philosophica. 46 (2), Pp 239-251, (2008).

[13] Baker I: To what extent can we overcome the "bystander effects" of collective responsibility in matters of global injuctice? Emergent Australasian Philosophers. 1(4), Pp 1-11, (2001).

[14] Setyo Trisnadi. The Legal Protection of Indonesian Physicians The Medical Dispute Settlement Based on Principle Standard Norms and Rules of Physician profession in Doctor Patient Relationship. International Journal of Humanities Social Sciences and Education (IJHSSE). 3(1), Pp 146-155, (2016)

[15] Hawkins C: For every ill a pill. Ann Rheum Dis. 39, 198-199, (1980).

[16] Gericke CA, Riesberg A, Busse R: Ethical issues in funding orphan drug research and development. J Med Ethics. 31, Pp 164-168, (2005).

\section{AUTHPRS' BIOGRAPHY}

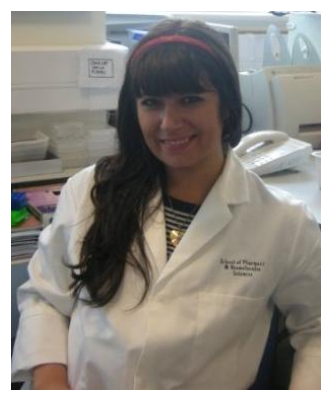

Branislava Medic, MD, MSc, PhD Student, Teaching and Research Assistant, Specialist of Clinical Pharmacology, Faculty of Medicine, University of Belgrade, Serbia. She is employed at Department of Pharmacology, Clinical Pharmacology and Toxicology, Faculty of Medicine, University of Belgrade, Serbia. Currently, she is finishing her $\mathrm{PhD}$ thesis which deals with experimental model of acute kidney failure and novel therapeutic approaches to this condition. Beside that, she is actively involved in research topics dealing with bioethical issue in medicine and pharmacology such as: testing drugs on experimental animals, clinical trials on vulnerable subjects, influence of education concerning important bioethical issues in our community etc. This work is part of research regarding medical, societal and bioethical aspects on rare diseases in Serbia (supported by Ministry of Science and Technological Development of Serbia Project No. 175023; Head of the Project is Prof. Milica Prostran, MD, PhD). 